\title{
Type A behaviour and prevalent heart disease in the Caerphilly study: Increase in risk or symptom reporting?
}

\author{
JOHN E GALLACHER, JOHN W YARNELL, AND BARBARA K BUTLAND \\ From the MRC Epidemiology Unit, 4 Richmond Road, Cardiff
}

SUMMARY Type A behaviour was assessed by modified Framingham scale in a total sample of 1956 employed men in the Caerphilly study. Prevalent heart disease was measured by cardiovascular questionnaire to obtain evidence of myocardial infarction and angina, and by electrocardiogram (ECG) for evidence of ischaemia. Type A was inversely related to age and systolic blood pressure and was positively related to social class and height. It was not related to serum cholesterol or alcohol consumption. After control for age, systolic blood pressure, height, smoking and social class, type A was found to be independent of angina but positively associated with an increased risk of possible myocardial infarction (MI). Type A was also associated with increased risk of confirmed MI. An inverse association was found between type $A$ and asymptomatic ischaemic heart disease (IHD). The association between type $A$ and symptomatic IHD could be due to symptom reporting.

Type $\mathbf{A}$ is a clinically derived behavioural syndrome characterised by time urgency, job involvement, and hostility, and which is thought to be characteristic of white collar North American populations. Several studies on populations in the United States show greater incidence of IHD with type A behaviour ${ }^{12}$ and lower levels of recurrent IHD with the reduction of type $A .{ }^{3}$ As US populations appear to have comparatively high levels of type $A^{4}$ the relevance of this construct for IHD in populations outside the US is unclear.

Evidence linking type A to IHD in European populations is inconsistent. Of six prospective studies only three show type A to predict IHD. The Regional Heart Study followed 5936 men aged 45-59 years and showed no association between Bortner type A scores and MI over a 5-year period. ${ }^{5}$ The Kaunas-Rotterdam Intervention study, using the Jenkins Activity Survey, found no prediction of IHD by type $A$ after 10 years in either intervention or control groups totalling 3171 men aged 45-57 years. ${ }^{6}$ The Belgian French Pooling Project found higher Bortner type A scores for incident cases than controls after 5 years in a cohort of 2811 men aged 40-50 years. ${ }^{7}$ The Belgian Heart Disease Prevention Project also found type A to predict IHD after 6 years using the Jenkins Activity Survey with 901 men aged $40-59$ years. $^{8}$ The two remaining European studies are difficult to assess due to small size ${ }^{9}$ and modified type $A$ measurement. ${ }^{10}$
The inconsistency in the results of well conducted and large European studies illustrates the need for further data. Reported here are the relations between type A behaviour, standard IHD risk factors, and prevalent heart disease from the Caerphilly study.

\section{Methods}

Full details of the Caerphilly study are given elsewhere. ${ }^{11} 12$ All men between the ages of 45 and 59 years inclusive who live in the town of Caerphilly and the surrounding area were invited to attend a heart disease screening clinic.

The London School of Hygiene \& Tropical Medicine (LSHTM) chest pain questionnaire was administered and a 12-lead electrocardiogram (ECG) recorded and Minnesota-coded by two experienced coders. ${ }^{13}$ Blood pressure was measured after several minutes rest in the sitting position. Height, weight and demographic details were recorded. Type A behaviour was assessed using a modified Framingham scale comprising the last five items of the full ten item scale. These items were selected as most relevant to this working population. A fasting blood sample was taken on a later occasion.

IHD was categorised as (1) none: indicating no chest pain of ischaemic origin; (2) any: indicating chest pain of possible ischaemic origin or ECG evidence of ischaemia; (3) asymptomatic: indicating ECG 
ischaemia only, as defined by Minnesota codes 1-1, 1-2, 1-3 (major, moderate and minor $Q$ waves), 4-1 to 4-4 (S-T wave changes), 5-1 to 5-5 (T wave inversion), and 7-1 (left bundle branch block); (4) symptomatic IHD. Symptomatic IHD was subdivided into four categories: (a) classical angina (grades $\mathrm{i}$ or ii), as defined by the LSHTM questionnaire; (b) history of possible MI as defined in the LSHTM questionnaire by report of severe chest pain across the front of the chest lasting half an hour or more; (c) confirmed MI: where a doctor had been seen about the chest pain and had confirmed it as an MI or synonym; (d) unconfirmed MI: where a doctor had not been seen or had not confirmed the chest pain as ischaemic in origin.

Type A score was used to identify low, medium and high scoring groups of roughly equal size. As four of the five items used to assess type A referred to work, type A scores were calculated only for employed men. Type A score was calculated so that each item was given equal weight as recommended. ${ }^{14}$ For convenience a scale from 0 to 10 was used.

Univariate associations between IHD and type A were examined for various categories of IHD. Multivariate associations were examined by multiple logistic regression which led to the estimation of disease odds, defined in this study as

$$
\left[\frac{\text { probability of IHD }}{\text { probability of no IHD }}\right] \text {, and thus relative odds. }
$$

Relative odds were defined as the odds of disease in one group divided by the odds of disease in another.

\section{Results}

Of the 2818 men identified as being eligible for the study, $2512(89 \%)$ were examined, producing a sample of 1956 employed men for whom type A scores were calculated. Scoring criteria for identifying low, medium and high scoring groups of roughly equal size were $0-1,2-3$, and $>3$, producing groups of 664,640 and 652 men respectively.

Prevalence for each IHD category according to type A score is given in table 1. Although the prevalence of all the IHD categories combined into "any IHD" did not vary with type A, with the exception of angina, associations were found between prevalence within each of the other IHD categories and type A score. For "asymptomatic IHD", prevalence went down from $11 \%$ in low and middle type $A$ groups to $7 \%$ in the high type A group ( $p<0.025)$. For "possible MI", prevalence rose from $4 \%$ in the low type A group to $9 \%$ and $10 \%$ in middle and high score groups respectively $(\mathrm{p}<0.001)$. As the diagnosis of "possible MI" was based on self-reported severe chest pain lasting 30 minutes or more, we would have had greater confidence that the relationship reflected an association with the disease if it were confirmed in men for whom further evidence of an MI was available. For "confirmed MI", prevalence rose slightly from $2 \%$ in the low type A score group to $4 \%$ in the middle group and $3 \%$ in the high group $(p<0.05)$. For "unconfirmed MI", prevalence rose from $2 \%$, through $5 \%$ to $8 \%$ with higher type A score $(\mathrm{p}<0.001)$.

The robustness of these associations to the effects of confounding variables was investigated by multivariate analysis. Covariates for this analysis were identified. Rank correlation showed type A to covary with social class $\left(r_{s}=0.28 ; p<0.001\right)$, height $\left(r_{s}=0.06\right.$; $p<0.01)$, age $\left(r_{s}=-0.1 ; p<0.001\right)$ and systolic pressure $(r=-0.06 ; p<0.01)$. Type A score was independent of weight, body mass index, alcohol consumption and serum cholesterol.

The relationship between type $\mathbf{A}$ and smoking was difficult to interpret. For cigarette smokers the proportion with a high type A score increased from $28 \%$ for men smoking 1-14 cigarettes daily, through $29 \%$ for men smoking 15-24 cigarettes daily to $33 \%$ for men smoking at least 25 cigarettes daily. However, for non-smokers, ex-smokers and pipe/cigar smokers the proportions with a type A score were higher than for cigarette smokeis, at $34 \%, 36 \%$ and $39 \%$ respectively. Although a test of association between type A category (low, middle, high) and smoking category did not achieve statistical significance $\left(\chi^{2}=11 \cdot 76, \mathrm{df}=10, \mathrm{p}>0.05\right)$ a possible effect of smoking on the association of type A with IHD could not be dismissed.

The relationship between type $A$ and social class was also considered more closely. A simple rank correlation of type A with social class at six levels (I, II, III non-manual, III manual, IV, V) produced a coefficient of $r_{s}=0.28, p<0.001$. However, Framingham type $A$ score has been reported to predict

Table 1 Prevalence (per cent) of IHD by Type A score in 1956 men aged 45-59 years

\begin{tabular}{|c|c|c|c|c|c|}
\hline \multirow[b]{2}{*}{ Category of IHD } & \multicolumn{4}{|c|}{ Type A score } & \multirow{2}{*}{$\begin{array}{l}\chi^{2}, d f=2 \\
\text { (against "No } \\
\text { IHD" category) }\end{array}$} \\
\hline & $0-1$ & $2-3$ & $4+$ & Total & \\
\hline None & $531(80)$ & $491(77)$ & $513(79)$ & $1535(78)$ & - \\
\hline Any & $133(20)$ & 149 (23) & $139(21)$ & $421(22)$ & $2 \cdot 1$ \\
\hline $\begin{array}{l}\text { Asymptomatic } \\
\text { Symptomatic } 1\end{array}$ & 74 (11) & 70 (11) & $44(7)$ & $188(10)$ & $7.7(p<0.025)$ \\
\hline Angina & $40 \quad(6)$ & 36 (6) & 39 (6) & 115 (6) & 0.0 \\
\hline Possible MI & 25 (4) & 56 (9) & $66(10)$ & 147 (8) & $19.2(\mathrm{p}<0.001)$ \\
\hline Confirmed MI & 10 (2) & 24 (4) & 17 (3) & $51 \quad(3)$ & $6.7(\mathrm{p}<0.05)$ \\
\hline Unconfirmed MI & I 15 (2) & 32 (5) & 49 (8) & 96 (5) & $17.9(\mathrm{p}<0.001)$ \\
\hline
\end{tabular}

Total

$664(100) 640(100) 652(100) 1956$ (100)

1 Symptomatic IHD categories are not mutually exclusive 
total IHD only in white collar workers. ${ }^{2}$ A preliminary multi-variate analysis was therefore conducted on the effect of a type $\mathbf{A} \times$ social class (manual, non-manual) interaction on the prevalence of "any IHD". When this interaction term was added to a multiple logistic regression model that already contained social class (manual, non-manual), and type $\mathrm{A}$, the improvement of fit was negligible $\left(\chi^{2}=0.12, \mathrm{df}=2, \mathrm{p}>0.05\right)$. This was interpreted as providing no evidence of a difference between manual and non-manual groups in relations of type A with "any IHD". In all subsequent analyses social class was considered as a six level factor.

To show the overall effect of type A on IHD a multiple logistic regression of IHD on type A score was conducted in which social class, age, height, systolic blood pressure and smoking were included as covariates. In this analysis the odds in each category of prevalent IHD in the lowest type A score group is used as a reference level and is effectively set to unity. The relative odds of prevalent IHD, in comparison with the reference level, is then calculated for the middle and high type A score groups. The hypothesis that there was no difference in relative odds of IHD between low, middle and high type A groups was tested by $\chi^{2}$. This gave a general test of association. To describe relationships more closely, hypotheses that the relative odds of IHD were the same for low versus middle and for low versus high type A score groups were tested by Student's $t$-test. Table 2 summarises the results of this analysis.

For "any IHD" there was no overall association between the relative odds of disease and type A score, although a slight increase in relative odds of $\psi=1.34$ $(p<0.05)$ was noted for the middle type A score group over the low score group. A slight overall association was shown for "asymptomatic IHD" $\left(\chi^{2}=6 \cdot 46\right.$,

Table 2 Relative odds of IHD by Type A score in 1956 men aged 45-59 years with social class, age, height, BP and smoking held constant

\begin{tabular}{|c|c|c|c|c|}
\hline $\begin{array}{l}\text { IHD Category } \\
\text { (dependent } \\
\text { variable) }\end{array}$ & $\begin{array}{l}\chi^{2} \\
(d f=2)\end{array}$ & $\begin{array}{l}\text { Type A } \\
\text { group }\end{array}$ & $\begin{array}{l}\text { Relative odds } \\
(95 \% \text { interval) }\end{array}$ & $\begin{array}{l}t \\
\text { value }\end{array}$ \\
\hline Any & $4 \cdot 74$ & $\begin{array}{l}\text { Middle } \\
\text { High }\end{array}$ & $\begin{array}{l}1.34(1.02,1.77) \\
1.25(0.94,1.67)\end{array}$ & $\begin{array}{l}2 \cdot 12^{*} \\
1 \cdot 52\end{array}$ \\
\hline Asymptomatic & $6.46^{*}$ & $\begin{array}{l}\text { Middle } \\
\text { High }\end{array}$ & $\begin{array}{l}1.11(0.77,1.61) \\
0.66(0.43,1.01)\end{array}$ & $\begin{array}{r}0.56 \\
-1.91\end{array}$ \\
\hline Symptomatic ${ }^{1}$ & & & & \\
\hline Angina & $0 \cdot 37$ & $\begin{array}{l}\text { Middle } \\
\text { High }\end{array}$ & $\begin{array}{l}1.10(0.69,1.78) \\
1.16(0.71,1.89)\end{array}$ & $\begin{array}{l}0.41 \\
0.60\end{array}$ \\
\hline Possible MI & $28 \cdot 10 \neq$ & $\begin{array}{l}\text { Middle } \\
\text { High }\end{array}$ & $\begin{array}{l}2.77(1.69,4.55) \\
3.40(2.07,5.59)\end{array}$ & $\begin{array}{l}4 \cdot 03 \ddagger \\
4 \cdot 82 \ddagger\end{array}$ \\
\hline Confirmed MI & $9.75 t$ & $\begin{array}{l}\text { Middle } \\
\text { High }\end{array}$ & $\begin{array}{l}3.10(1.47,6.55) \\
2.32(1.04,5.21)\end{array}$ & $\begin{array}{l}2.96 \dagger \\
2.05^{*}\end{array}$ \\
\hline Unconfirmed MI & $22 \cdot 86 t$ & $\begin{array}{l}\text { Middle } \\
\text { High }\end{array}$ & $\begin{array}{l}2.60(1.39,4.83) \\
4.07(2.23,7.43)\end{array}$ & $\begin{array}{l}3.01 \dagger \\
4.57 \ddagger\end{array}$ \\
\hline
\end{tabular}

1 Symptomatic IHD categories are not mutually exclusive

$* \mathrm{p}<0.05,+\mathrm{p}<0.01, \pm \mathrm{p}<0.001$. $\mathrm{p}<0.05)$ which appeared to reflect lower relative odds of disease in the high type A group $(\psi=0 \cdot 66)$, this result narrowly failing to achieve conventional levels of statistical significance. The relationships between type $A$ and the various categories of symptomatic IHD followed a similar pattern to those of the univariate analyses. Type A was not associated with angina but was strongly associated with "possible MI" $(p<0.001)$. For "possible MI" the relative odds of disease increased with middle and high type A score to $\psi=2.77$ and $\psi=3.40$ respectively. If "possible MI" is considered in terms of "confirmed MI" and "unconfirmed MI" the strongest association is with "unconfirmed MI" $\left(\chi^{2}=22.86, p<0.001\right)$ for which the relative odds of disease for middle and high type A groups were $\psi=2.60$ and $\psi=4.07$ respectively. An association was also found for "confirmed MI" $\left(\chi^{2}=9.75, \mathrm{p}<0.01\right)$ for which the relative odds were $\psi=3.10$ in the middle type A group and $\psi=2.32$ in the high type A group.

The association of type A with lifestyle-related risk factors for groups of different IHD status was also investigated. The purpose of this analysis was to show any effects of IHD on lifestyle for symptomatic men and to give an indication of possible IHD risk for asymptomatic and IHD-free men, in relation to type $A$ status. Associations of smoking, alcohol consumption and body mass index with type $A$ appeared to differ between IHD categories. Table 3 gives the percentage of non-smokers, ex-smokers and current cigarette smokers in each type A/IHD status category. Of particular interest is the percentage of ex-smokers which increased with type A score for men with symptomatic IHD: a trend that was not observed for asymptomatic or disease-free men. Table 4 gives median alcohol consumption for each type A/IHD status category. Median values are presented since the skew of the distribution could not be corrected by transformation. In men free of IHD no association was found between median alcohol intake and type $A$ score. In men with asymptomatic IHD a trend of increasing alcohol consumption with greater type A score was shown, whilst in men with symptomatic IHD there was a trend of lower alcohol consumption with greater type A score. There was no consistent association between body mass index (BMI) and type A score, either in symptomatic men or in those with no IHD. Amongst asymptomatic men, however, mean BMI rose from $\bar{x}=26 \cdot 2(S D=3 \cdot 2, n=73)$ for low type A scorers through $\bar{x}=27.9(\mathrm{SD}=4 \cdot 3, \mathrm{n}=69)$ to $\overline{\mathrm{x}}=28.4(\mathrm{SD}=4 \cdot 2, \mathrm{n}=44)$ for high type A scorers.

\section{Discussion}

The present study relates Framingham type A scores to prevalent IHD and IHD risk factors in a population 
Table 3 Frequency (percentage) of non-smokers, exsmokers and current smokers according to type A score and IHD status in $1956^{1}$ men aged $45-59$ years

\begin{tabular}{|c|c|c|c|c|}
\hline & \multicolumn{4}{|c|}{ Type A score } \\
\hline & $0-1$ & $2-3$ & $4+$ & Total \\
\hline \multicolumn{5}{|l|}{ No IHD } \\
\hline Non-smoker & $94(18)$ & $93(19)$ & $98(19)$ & $285(19)$ \\
\hline Ex-smoker & $151(28)$ & $134(27)$ & $154(30)$ & 439 (29) \\
\hline Current smoker & $285(54)$ & $261(53)$ & $260(51)$ & $806(53)$ \\
\hline \multicolumn{5}{|l|}{ Asymptomatic IHD } \\
\hline Non-smoker & $8(11)$ & $12(17)$ & $10(23)$ & $30(16)$ \\
\hline Ex-smoker & $26(35)$ & $20(29)$ & $13(30)$ & 59 (32) \\
\hline Current smoker & $40(54)$ & 37 (54) & $20(47)$ & $97(52)$ \\
\hline \multicolumn{5}{|l|}{ Symptomatic IHD } \\
\hline Non-smoker & $11(19)$ & $5 \quad(6)$ & $8(8)$ & $24(10)$ \\
\hline Ex-smoker & $12(20)$ & $24(30)$ & $36(38)$ & $72(31)$ \\
\hline Current smoker & $36(61)$ & $50(63)$ & $51(54)$ & $137(59)$ \\
\hline \multicolumn{5}{|l|}{ Total } \\
\hline Non-smoker & $113(17)$ & $110(17)$ & $116(18)$ & 339 (17) \\
\hline Ex-smoker & 189 (29) & $178(28)$ & $203(31)$ & $570(29)$ \\
\hline Current smoker & 361 (54) & 348 (55) & 331 (51) & $1040(53)$ \\
\hline
\end{tabular}

${ }^{1}$ Smoking data missing for 7 cases

Table 4 Median alcohol intake (g/day) according to IHD and type A category in $1956^{1}$ men aged 45-59 years

\begin{tabular}{|c|c|c|c|c|c|}
\hline \multirow[b]{2}{*}{ IHD categor } & & \multicolumn{4}{|c|}{ Type A score } \\
\hline & & $0-1$ & $2-3$ & $4+$ & Total \\
\hline \multirow[t]{2}{*}{ No IHD } & $\begin{array}{l}\text { Median } \\
\text { Range }\end{array}$ & $\begin{array}{r}15.5 \\
0-334\end{array}$ & $\begin{array}{r}15.5 \\
0-152\end{array}$ & $\begin{array}{r}15.5 \\
0-165\end{array}$ & $\begin{array}{r}15.5 \\
0-334\end{array}$ \\
\hline & Cell frequency & 513 & 469 & 496 & 1478 \\
\hline \multicolumn{6}{|c|}{ Asymptomatic } \\
\hline \multirow[t]{2}{*}{ IHD } & $\begin{array}{l}\text { Median } \\
\text { Range }\end{array}$ & $\begin{array}{r}12.9 \\
0-144\end{array}$ & $\begin{array}{r}15.5 \\
0-129\end{array}$ & $\begin{array}{r}17.8 \\
0-96\end{array}$ & $\begin{array}{r}15.3 \\
0-144\end{array}$ \\
\hline & Cell frequency & 73 & 67 & 43 & 183 \\
\hline \multicolumn{6}{|c|}{ Symptomatic } \\
\hline \multirow[t]{2}{*}{ IHD } & $\begin{array}{l}\text { Median } \\
\text { Range }\end{array}$ & $\begin{array}{r}16.6 \\
0-180\end{array}$ & $\begin{array}{r}12.9 \\
0-115\end{array}$ & $\begin{array}{r}10.3 \\
0-144\end{array}$ & $\begin{array}{r}12.9 \\
0-180\end{array}$ \\
\hline & $\begin{array}{l}\text { Range } \\
\text { Cell frequency }\end{array}$ & $\begin{array}{r}0-180 \\
56\end{array}$ & $\begin{array}{r}0-115 \\
74\end{array}$ & $\begin{array}{r}0-144 \\
94\end{array}$ & 224 \\
\hline \multirow[t]{3}{*}{ Total } & Median & $15 \cdot 5$ & 15.5 & $15 \cdot 3$ & 15.5 \\
\hline & Range & $0-334$ & $0-152$ & $0-165$ & $0-334$ \\
\hline & Cell frequency & 642 & 610 & 633 & 1885 \\
\hline
\end{tabular}

${ }_{1}$ Alcohol data incomplete or missing for 71 cases

outside the USA. ${ }^{15}$ Type A was found to be associated with IHD independently of social class, age, height, systolic blood pressure and smoking in this study of 1956 employed men aged 45-59 years from South Wales in the UK. Associations with type A may be summarised as being absent for "any IHD" and "angina", positive for "possible MI" and negative for "asymptomatic IHD".

We were interested in whether the pattern of association found in this study indicates an effect of type A or an effect of disease. The greater relative odds of "confirmed MI" with higher type A score is consistent with both explanations. Type A may well be a determinant of MI, but the experience, diagnosis and treatment of a coronary event may equally well affect the perception of stress and hence type A scores. If this association represents an effect on disease, the relationship may not be monotonic. The relative odds of "confirmed MI" were less in the high score group $(\psi=2 \cdot 32)$ than in the middle score group $(\psi=3 \cdot 1)$. This difference in relative odds between middle and high type A groups may be a chance effect, but may also correctly describe the relationship between these variables. A precedent for non-monotonic relationship is the Framingham Study in which the strongest prediction of MI by type A was found using a dichotomous type $\mathrm{A} v$ type $\mathrm{B}$ classification rather than continuous type A scale. ${ }^{2}$

Alternatively, the associations with MI reported here may be a function of having symptoms of heart disease, since a positive association with type $A$ was not found in asymptomatic IHD. The experience of symptoms may serve to increase type A scores. Against this hypothesis, however, is the lack of association between type $A$ and angina. To argue that it is harder to score a false positive on the series of questions used to diagnose angina than on the single question used to diagnose possible $\mathrm{MI}$ is not sufficient to explain the different effects of these symptoms. If symptoms have an effect on type A scores, this effect occurs irrespective of the specificity ( 1 minus the probability of a type I error) of the test. The difference could be explained by different effects of the two types of symptom, angina occurring repeatedly rather than being a single event. If so, it would be surprising for an effect on type A score to be shown only for MI.

A third explanation of the associations reported here is they may be confounded. The increase in self-reported "unconfirmed MI", ie that for which there was no further clinical confirmation, with type A score is particularly interesting since Framingham type A scores are related to anxiety level. ${ }^{216}$ The greater anxiety of type A men could make them more aware of potential disease risk and encourage the awareness and reporting of symptoms. Greater symptom reporting may inflate the association of type A with IHD, as assessed in this study, by producing more false positive responses to the LSHTM questionnaire. Symptom reporting may have less effect on "angina" than "possible MI" prevalence due to the more specific nature of angina symptoms. Arguably this effect would be most pronounced in the "unconfirmed MI" group, showing greater relative odds of $\psi=4.07$ with high type A score. It is a matter of judgement, however, as to whether this source of bias would fully account for the strength of the association. A further source of bias due to symptom reporting would occur if type A men were more likely to consult their doctor, resulting in greater likelihood of diagnosis, correct or otherwise. This effect would be reflected in the association with "confirmed MI", but the likelihood of such an effect or its possible magnitude cannot be assessed from these data. 
That type A score may effect the response to symptoms is shown by the trends of greater cessation of smoking and lower alcohol intake with greater type A score in symptomatic men. This suggests that high type A scorers may be more likely to change lifestyle as a result of IHD symptoms. If so this could be due either to a greater awareness of symptoms or to a greater willingness to respond to symptoms. Either process would be consistent with the higher level of symptom reporting associated with type A behaviour. This suggestion, however, does not explain the increase in alcohol consumption and body mass index with higher type A score in asymptomatic men.

Also of interest in these data are relations between type A and IHD risk factors. The slight reduction in type $A$ with age has been shown previously over a wider age-range sample. ${ }^{17} \mathrm{~A}$ plausible explanation is that the expression of type $A$ is dependent on physical and motivational factors which decline with age. Whether any decline in motivation over time is a function of vigour or circumstances is an open question. The lack of association of type A with IHD risk factors in IHD-free men confirms the view that the process underlying any predictive association of type A for IHD is not reflected in the measurement of standard risk factors as conventionally undertaken.

A limitation in this study is the use of a modified type A scale. Evidence for the validity of this scale comes from its association with IHD described earlier and from its association with other type A scales. To compare type A scales, Jenkins Activity Survey (JAS) data were collected for 99 men in this study. The rank correlation coefficient between JAS and modified Framingham scores was $r=0.43$, this being comparable to those reported between the JAS and the full Framingham scale of $r=0.41$ and $r=0.53 .^{5}$ Although the modified Framingham type A scale may be a less sensitive measure of type $A$ behaviour, it nevertheless appears to provide scores which behave in a similar manner to those of the full scale. Also of interest is the divergence of results between the present study and one on a random sample of men aged 30-69 years, also from Caerphilly, in whom type $A$ was associated with angina. ${ }^{18}$ Methodological compatability between studies is shown by comparing mean type A scores of men of common age (45-54 years) without angina, these being identical for both studies at $\bar{x}(\mathrm{SD})=2 \cdot 9(2 \cdot 2)$. As the findings of the present study are based on 115 angina cases as opposed to 30 cases in the previous study, the present findings may be considered to be more reliable.

In conclusion, this study has shown that Framingham type A score is related to prevalent MI. The causality of these associations cannot be identified from these data, and could be due to an effect of symptom reporting.
This work was supported by grants from the Commision of the European Communities and the Health Promotion Research Trust.

Correspondence and reprint requests to $\operatorname{Dr} \mathrm{J} E \mathrm{~J}$ Gallacher, MRC Epidemiology Unit, 4 Richmond Road, Cardiff CF2 3AS.

\section{References}

${ }^{1}$ Rosenman RH, Brand RJ, Jenkins DC, Friedman $M$, Straus R, Wurm M. Coronary heart disease in the Western Collaborative Group Study: Final follow up experience of $8 \frac{1}{2}$ years. $J A M A$ 1975; 233: 872-7.

2 Haynes SG, Feinleib M, Kannel WB. The relationship of psychosocial factors to coronary heart disease in the Framingham study: III. Eight year incidence of coronary heart disease. Am J Epidemiol 1980; 111: 37-58.

${ }^{3}$ Friedman MF, Thoresen CE, Gill JJ, et al. Alteration of type A behaviour and its effect on cardiac recurrences in post myocardial infarction patients: Summary results of the recurrent coronary prevention project. Am Heart $J$ 1986; 112: 653-65.

${ }^{4}$ Cohen JB, Syme SL, Jenkins CD, et al. Cultural context of type A behaviour and risk for CHD: A study of Japanese American males. J Behav Med 1979; 2: 375-84.

5 Johnston DW, Cook DG, Shaper AG. Type A behaviour and ischaemic heart disease in middle-aged British men. Br Med J 1987; 295: 86-9.

${ }^{6}$ Appels A, Mulder P, van't Hof M. The predictive power of the A/B typology in Holland. Results of a 10 year follow-up. Paper presented at the Conference on biobehavioural factors in coronary heart disease, Winterscheid, 1984.

${ }^{7}$ French Belgian Collaborative Group. Assessment of type A behaviour by the Bortner Scale and ischaemic heart disease. Eur Heart J 1984; 5: 440-6.

${ }^{8} \mathrm{Kittel}$ F, Dramaix M, Kornitzer M, et al. Type A and social factors in relation to IHD incidence (Abstract). Eur Heart $J$ 1985; 6, Suppl 1:6.

${ }^{9}$ De Backer G, Kornitzer M, Kittel F, et al. Behaviour, stress, and psychosocial traits as risk factors. Prev Med 1983; 12: 32-6.

${ }^{10}$ Koskenvuo M, Kaprio J, Langinvainio H, et al. Mortality in relation to coronary prone behaviour: a six year follow up of the Bortner scale in middle aged Finnish men. Cardiovasc Diseases Epidemiological Newsletter 1983; 34 : 40.

11 The Caerphilly and Speedwell Collaborative Group. Caerphilly and Speedwell collaborative heart disease studies. J Epidemiol Community Health 1984; 38: 259-62.

12 The Caerphilly Collaborative Group. Project description and manual of operations. Cardiff: MRC Epidemiology Unit, 1985.

13 Rose GA, Blackburn H, Gillum RF, Prineas RJ. Cardiovascular survey methods. Geneva: WHO, 1982.

14 Haynes SG, Levine S, Scotch N, Feinleib M, Kannel WB. The relationship of psychosocial factors to coronary heart disease in the Framingham Study: I. Methods and risk factors. Am J Epidemiol 1978; 107: 362-83.

15 Haynes SG, Feinleib M, Levine S, Scotch N, Kannel WB. The relationship of psychosocial factors to coronary heart disease in the Framingham study: II. Prevalence of coronary heart disease. Am J Epidemiol 1978; 107: $384-402$. 
${ }^{16}$ Chesney MA, Black GW, Chadwick JM, Rosenman RH. Psychological correlates of the Type A behaviour pattern. J Behav Med 1983; 4: 217-29.

${ }^{17}$ Gallacher JEJ, Beswick AD, Jones DM, Turkington EE. Type $A$ behaviour and pressor response in a representative sample of middle aged men. $J$ Psychosom Res 1988; 32: 51-61.
${ }^{18}$ Gallacher JEJ, Yarnell JWG, Phillips KM. Type A behaviour and heart disease prevalent in men in the Caerphilly study. $\mathrm{Br}$ Med J 1984; 289: 732-3.

Accepted for publication May 1988 